Article

\title{
Edible Films Based on Black Chia (Salvia hispanica L.) Seed Mucilage Containing Rhus microphylla Fruit Phenolic Extract
}

\author{
Ana V. Charles-Rodríguez ${ }^{1, *}$, Luz L. Rivera-Solís ${ }^{1}$, Joana T. Martins ${ }^{2}$, Zlatina Genisheva ${ }^{2} \mathbb{D}$, \\ Armando Robledo-Olivo ${ }^{1}(\mathbb{D})$, Susana González-Morales ${ }^{1}\left(\mathbb{D}\right.$, Gustavo López-Guarin ${ }^{1}$, \\ Dolores G. Martínez-Vázquez ${ }^{1}$, António A. Vicente ${ }^{2}$ and María L. Flores-López ${ }^{3,4, *(D)}$ \\ 1 Universidad Autónoma Agraria Antonio Narro, Calzada Antonio Narro No. 1923, Colonia Buenavista, \\ 25315 Saltillo, Coahuila, Mexico; luzletirs@gmail.com (L.L.R.-S.); armando.robledo@outlook.com (A.R.-O.); \\ qfb_sgm@hotmail.com (S.G.-M.); glguarin2011@hotmail.com (G.L.-G.); \\ gabrielamartinezicta@gmail.com (D.G.M.-V.) \\ 2 CEB - Centre of Biological Engineering, University of Minho, Campus de Gualtar, 4710-057 Braga, Portugal; \\ joanamartins@deb.uminho.pt (J.T.M.); zgenisheva@gmail.com (Z.G.); avicente@deb.uminho.pt (A.A.V.) \\ 3 UIEPA-Unidad Ahuacatlán, 73330 Ahuacatlán, Puebla, Mexico \\ 4 Biocampo S.A. de C.V., Blvd. Dr. Jesús Valdés Sánchez Km. 10, Fracc. Presa de las Casas, 25350 Arteaga, \\ Coahuila, Mexico \\ * Correspondence: anavero29@gmail.com (A.V.C.-R.); mlfl.flores@gmail.com (M.L.F.-L.)
}

Received: 22 February 2020; Accepted: 26 March 2020; Published: 29 March 2020

\begin{abstract}
Functional films based on black chia (Salvia hispanica L.) seed mucilage (BCm) containing Rhus microphylla (Rm) fruit phenolic extract were built and characterized. A hydro-alcohol extract (HAE) of Rm was incorporated as the bioactive agent due to its noteworthy phenolic profile, and good antioxidant and antifungal activities. The effects of the $\mathrm{BCm}$ concentration $(0.2 \%$ and $0.4 \%$, $\mathrm{w} / \mathrm{v})$, HAE incorporation, and their interaction with glycerol $(1.0 \%, \mathrm{w} / \mathrm{v})$ and calcium chloride $(0.05 \%$, $\mathrm{w} / \mathrm{v}$ ) on the films' physicochemical properties were evaluated. The filmogenic solutions successfully fitted to the Herschel-Bulkley model $\left(R^{2}<0.999\right)$, exhibiting a pseudoplastic and shear thinning character, typical of polymer solutions. Interestingly, their rheological properties were not $(p>0.05)$ changed by the HAE addition, but their surface tension was enhanced $(p<0.05)$, which could favor their coating ability. The polyanionic nature of the systems (zeta potential-Zp values from -26.9 to $-33.3 \mathrm{mV}$ ) allowed them to interact with $\mathrm{Ca}^{2+}$ cations, thus forming stable and resistant films. All the films showed low water solubility $\left(15.0 \%\right.$ to $22.3 \%$ ) and high permeability (3.7 to $4.0 \times 10^{-10} \mathrm{~g} \mathrm{~m}^{-1}$ $\mathrm{s}^{-1} \mathrm{~Pa}^{-1}$ ), as well as high biodegradability (moisture content from $66.0 \%$ to $80.9 \%$ ); although the moisture content was reduced $(p<0.05)$ with HAE addition. The combination of higher $\mathrm{BCm}$ ratio and HAE addition (BCm0.4+Rm) led to a more resistant, thick, opaque, and dark film compared with the others obtained. This study reveals the BCm-based films' potential, highlighting those with HAE, representing a novel alternative to improve the quality of food products.
\end{abstract}

Keywords: Black chia seed; mucilage; Rhus microphylla fruit; phenolic extract; edible films

\section{Introduction}

The greatest losses in crops that occur in pre- and post-harvest stages are produced by microorganisms, mostly phytopathogenic fungi (e.g., Fusarium oxysporum and Corynespora cassiicola) [1] . The conventional management in the pre-harvest stage is based on synthetic pesticides; however, their indiscriminate use usually generates a microorganism's resistance to most synthetic pesticides, and negative effects on human health and the environment [2,3]. During the post-harvest stage, 
these practices are reduced to avoid residuality in the produce, increasing the risk of microbial contamination [4]. Hence, it is imperative to develop products based on natural compounds, which are effective in controlling phytopathogenic microorganisms, without generating residuality in the produce. In this context, some plants of Rhus genus such as R. muelleri and R. coriaria L., are characterized for their high phenolic, triterpenes, and other compounds' contents, which contribute to their reported antimicrobial activity $[5,6]$. In Mexico, the $R$. microphylla $(\mathrm{Rm})$ shrub fruit (commonly known as "agrito") is used by the Kickappos indigenous people in folk medicine [7], although its chemical composition and properties have not yet been studied. Considering Rhus species potential, Rm could be a new natural source of compounds with a wide range of bioactivities, such as antimicrobial and antioxidant actions.

Edible film packaging has proven effective as bioactive compounds carriers (e.g., antioxidants, antimicrobials, nutraceuticals, and nutrients), acting as an active agent protector and prolonging its action [8,9]. Moreover, films are able to create a shielding semi-permeable barrier to gases and water vapor, thus increasing the shelf life of coated produce [10]. The bio-based films are produced using a wide range of biopolymers, highlighting those based on polysaccharides due to their biodegradable ability, good mechanical and barrier properties, and their appropriate adhesion to the produce's surface $[11,12]$. Owing to this, the search for alternative sources of polysaccharides arises as a necessity, within which the chia (Salvia hispanica L.) mucilage $(\mathrm{Cm})$ has received considerable attention. The $\mathrm{Cm}$ presents outstanding properties that make it a potential material for edible packaging production, such as water retention capacity and viscosity [13-15]. It consists of a branched matrix of xylose, glucose, and glucuronic acid, although its composition varies according to the variety and region in which it grows [16]. In this regard, white and black varieties of chia seeds have been studied by de Falco et al. [17], which found that black chia seeds presented both higher antioxidant activity and total phenolic compounds than the white variety. However, the study and application of black chia seed mucilage $(\mathrm{BCm})$-based films as carriers of bioactive extracts from natural sources are still limited. It could represent a novel option for crop management in the field with a prolonged effect during the post-harvest stage. Thus, the goals of this research were to 1) characterize Rm fruit extracts in terms of phenolic profile, antioxidant activity, and antifungal effect on pathogenic fungi of commercial importance; and (2) evaluate the incorporation of bioactive Rm fruit extracts on BCm-based films' physicochemical properties.

\section{Materials and Methods}

\subsection{Materials}

Absolute ethanol (99.9\%) was obtained from Jalmek (Jalmek Científica S.A. de C.V., San Nicolás, NL, Mexico). Potato dextrose agar (PDA) was purchased from TM MEDIA (Titan Biotech Ltd., Delhi, India). Sodium carbonate $\left(\mathrm{Na}_{2} \mathrm{CO}_{3}\right)$, gallic acid (GA), and 2,2-diphenyl-1- picrylhydrazyl (DPPH) were supplied from Sigma (Sigma-Aldrich, Saint Louis, MO, USA). The Folin-Ciocalteu (FC) reagent was obtained from Merck (Merck KGaA, Darmstadt, Germany). Milli-Q water (Millipore, Bedford, MA, USA) was used to prepare all samples, standards, and eluents.

Fusarium oxysporum (National Center for Biotechnology Information, NCBI, accession no. MF996561) and Corynespora cassiicola (NCBI accession no. MK530179) were supplied from CICY (Yucatan Center for Scientific Research, Yucatan, Mexico).

Chia seeds (Salvia hispanica L.) of black variety from (Huaquechula, Puebla, Mexico) were used in this work.

\subsection{Plant Collection and Sample Preparation}

The fruit from Rm shrubs were collected randomly in wild areas located in the semi-arid region of Coahuila State, Mexico $\left(25^{\circ} 21^{\prime} 24^{\prime \prime} \mathrm{N} 101^{\circ} 01^{\prime} 59^{\prime \prime} \mathrm{W}\right)$. After drying the fruit in an oven (Biobase Biodustry 
Shandong Co., Ltd., Jinan, China) at $60{ }^{\circ} \mathrm{C}$ for $48 \mathrm{~h}$ [2], they were ground to a particle size equivalent to mesh no. 20 and stored until further use.

Preparation of Rhus microphylla (Rm) Fruit Extracts

The Rm fruit extracts were obtained according to Jasso de Rodríguez et al. [18] with slight changes. To an $11.5 \mathrm{~g}$ of dried fruit were poured $125 \mathrm{~mL}$ of distilled water or hydro-alcohol solution (50:50 $\mathrm{v} / \mathrm{v}$ ), and exhaustively extracted at $150 \mathrm{rpm}$ for $22 \mathrm{~h}$ at room temperature (Innova 44 Incubator, New Brunswick Scientific Co., Inc., Edison, NJ, USA). The obtained crude aqueous (AE) and hydro-alcohol (HAE) extracts were transferred to a rotary evaporator (IKA RV 10 basic, IKA Werke GmbH \& Co. KG, Staufen, Germany) for concentration at $98^{\circ} \mathrm{C}$ and $89^{\circ} \mathrm{C}$, respectively, then stored in the dark at $5{ }^{\circ} \mathrm{C}$ until further analysis.

\subsection{Characterization and Bioactivity of Rm Fruit Extracts}

\subsubsection{Total Phenolic Content (TPC)}

The total phenolic content (TPC) estimation was conducted using FC reagent and a microplateadapted method as described by Jesus et al. [19] with some modifications. In brief, AE and HAE (0.01 g) were homogenized in $5 \mathrm{~mL}$ of their respective extraction solvent (distilled water or hydro-alcohol solution), and centrifuged at $12,000 \mathrm{~g}$ for $5 \mathrm{~min}$. To a $100 \mu \mathrm{L}$ of supernatant were added $0.5 \mathrm{~mL}$ of FC reagent (1:10 diluted) and mixed during $2 \mathrm{~min}$; subsequently, $1.5 \mathrm{~mL}$ of $\mathrm{Na}_{2} \mathrm{CO}_{3}$ solution $(7.5 \%, \mathrm{w} / \mathrm{v})$ were incorporated. The reaction mixture was maintained at room temperature for $2 \mathrm{~h}$. Lastly, the absorbance (at $765 \mathrm{~nm}$ ) was measured in a Synergy HT microplate lector (Biotek, Winooski, VT, USA). The obtained values were compared to calibration curve $\left(0.2,0.4,0.6,0.8,1.0 \mathrm{~g} \mathrm{~L}^{-1}, R^{2}=0.99\right)$ using GA as standard. The TPC values were expressed as $\mathrm{g}$ GA equivalents per $\mathrm{kg}$ of extract. All experiments were carried out in triplicate.

\subsubsection{Phenolic Profile by Ultra High-Performance Liquid Chromatography (UHPLC)}

Samples were evaluated by means of UHPLC employing a Shimatzu Nexpera X2 equipment coupled with Diode Array Detector (Shimadzu, SPD-M20A, Tokyo, Japan). A reversed-phase Acquity UPLC BEH C18 column of $2.1 \mathrm{~mm} \times 100 \mathrm{~mm}, 1.7 \mu \mathrm{m}$ (Waters) and a pre-column filled with the same column material were used. The work temperature was $40{ }^{\circ} \mathrm{C}$ and the flow rate was $0.4 \mathrm{~mL} \mathrm{~min}{ }^{-1}$. Two HPLC grade solvents were used: solvent A water/formic acid (0.1\%) and solvent B acetonitrile. The elution gradient was according to Jesus et al. [19]. Samples' phenolic compounds were identified by comparing ultraviolet (UV) spectra and retention times with those of the corresponding standards. All analyzes were conducted in triplicate.

\subsubsection{Antioxidant Activity}

The antioxidant activity determination was based on a microplate-adapted DPPH method with minor modifications [9]. Each sample $(25 \mu \mathrm{L})$ was dissolved in its respective extraction solvent (at 20 to $\left.2500 \mathrm{mg} \mathrm{L}^{-1}\right)$ and mixed with $200 \mu \mathrm{L}$ of DPPH solution (150 $\mu \mathrm{M}$ in ethanol). Then, they were stirred and preserved under dark conditions at room temperature for $30 \mathrm{~min}$. The absorbance readings were performed at $515 \mathrm{~nm}$ (Synergy HT, Biotek, Winooski, VT, USA) and the antioxidant activity was reported as DPPH radical scavenging activity percentage (\% RSA) related to the control (ethanol without sample), calculated as follows:

$$
R S A(\%)=\frac{A_{\text {control }}-A_{\text {sample }}}{A_{\text {control }}} \times 100
$$


where $A_{\text {control }}=$ control absorbance and $A_{\text {sample }}=$ sample absorbance. The antiradical activity expressed as $I C_{50}$ value (i.e., concentration required to obtain $50 \%$ of $R S A$ inhibition) was determined for each extract. All the experiments were replicated three times.

\subsubsection{Antifungal Activity in vitro}

The antifungal activity determination was performed at different concentrations $(100,500,1000$, 2500, and $3000 \mathrm{mg} \mathrm{L}^{-1}$ ) according to the agar dilution method [6]. Fungal plugs (3-mm diameter) from C. cassicola and F. oxysporum were grown on PDA at $27 \pm 2{ }^{\circ} \mathrm{C}$ for $7 \mathrm{~d}$, and placed at the center of Petri dishes plates containing PDA with each extract treatment and PDA without extract (absolute control). Plates were incubated at $27 \pm 2{ }^{\circ} \mathrm{C}$ for $7 \mathrm{~d}$, and then the radial mycelial diameter was measured (mm). The percentage of fungal growth inhibition (\%) was determined using the following equation:

$$
\text { Inhibition }(\%)=\frac{D_{\text {control }}-D_{\text {treatment }}}{D_{\text {control }}} \times 100
$$

where $D_{\text {control }}=$ mycelia diameter $(\mathrm{mm})$ of the absolute control, and $D_{\text {treatmet }}=$ mycelia diameter $(\mathrm{mm})$ of each treatment. The test was conducted with five replicates.

\subsection{Black Chia Seed Mucilage (BCm) Extraction}

The $\mathrm{BCm}$ extraction was performed by hydration of whole black chia seeds in distilled water $(1: 2, \mathrm{w} / \mathrm{v})$, under stirring (500 rpm) for $60 \mathrm{~min}$ at room temperature, using the method described by Dick et al. [14] with some modifications. The resulting mixture was liquefied for $10 \mathrm{~s}$ at low speed, and subsequently, centrifuged (Beckman Coulter, Allegra X-I2R, Palo Alto, CA, USA) at 10,000 rpm for $10 \mathrm{~min}$ at $10^{\circ} \mathrm{C}$. The resulting mucilage was frozen $\left(-80^{\circ} \mathrm{C}\right.$ for $\left.12 \mathrm{~h}\right)$ in order to be lyophilized (Labconco Freezone 6.0, Expotech, Houston, TX, USA) at $-55^{\circ} \mathrm{C}$ and $0.133 \mathrm{mbar}$ for $24 \mathrm{~h}$ and stored until use.

\subsection{Film Preparation}

Film solutions were prepared using components concentrations based on preliminary tests (data not shown), which were selected considering the good ability to form films (i.e., with good stability and handling). Firstly, two formulations were obtained: formulation $\mathrm{BCm} 0.2(0.2 \% \mathrm{BCm}+0.05 \%$ $\mathrm{CaCl}_{2}+1.0 \%$ glycerol, w/v) and formulation $\mathrm{BCm} 0.4\left(0.4 \% \mathrm{BCm}+0.05 \% \mathrm{CaCl}_{2}+1.0 \%\right.$ glycerol, $\mathrm{w} / \mathrm{v})$. Films were prepared by dissolving lyophilized $\mathrm{BCm}$ in distilled water under stirring for $20 \mathrm{~min}$ at $20^{\circ} \mathrm{C}$. Then, $\mathrm{CaCl}_{2}$ (crosslinker) was added to the solution and when it was completely dissolved, glycerol (plasticizer) was incorporated to obtain a homogenous solution. Additionally, two functionalized formulations were obtained by adding Rm extract (AE or HAE) to the filmogenic solutions: $\mathrm{BCm} 0.2+\mathrm{Rm}$ and $\mathrm{BCm} 0.4+\mathrm{Rm}$. Rm extract type and concentration were selected based on its bioactive properties results (i.e., phenolic profile, antioxidant, and antifungal, see Section 3.1). Subsequently, the films were formed by the solvent casting technique by pouring $28 \mathrm{~mL}$ in Petri dishes $\left(9.6 \mathrm{~cm}\right.$ ) which were dried at $40{ }^{\circ} \mathrm{C}$ for $24 \mathrm{~h}$. Then, the films were stored at $20{ }^{\circ} \mathrm{C}$ and $53 \%$ relative humidity (RH) in a desiccator until further analysis.

\subsection{Film Characterization}

\subsubsection{Surface Tension}

Filmogenic solutions' surface tension was determined by the Ring method as described by Torres-León et al. [10], using a Krüss K6 tensiometer (Krüss GmbH, Hamburg, Germany) with a De Noüby platinum ring of $1.9 \mathrm{~cm}$. Five replicates measurements were obtained at room temperature, for each formulation. 


\subsubsection{Zeta Potential (Zp)}

The surface charge $(\mathrm{mV})$ of each filmogenic formulation was evaluated using a Zetasizer Nano ZS (Malvern Instruments Ltd., Worcestershire, UK). The Zp measurements were conducted in triplicate under room temperature conditions using a folded capillary cell (DTS 1060, Malvern Instruments Ltd., Worcestershire, UK).

\subsubsection{Film Thickness}

The film thickness $(\mu \mathrm{m})$ of each sample film was obtained as the mean of five random measurements using a digital micrometer (No. 293.561, Mitutoyo, Japan). The mean thickness values were used to calculate water vapor permeability (WVP) and tensile strength.

\subsubsection{Water Vapor Permeability (WVP)}

The WVP of BCm-based films was measured gravimetrically according to the American Society for Testing and Materials (ASTM) E96-92 method [11]. The film samples were sealed on the upper of a permeation cell holding distilled water $(50 \mathrm{~mL})$ to guarantee specific work conditions (i.e., $100 \% \mathrm{RH}$ at $20^{\circ} \mathrm{C}$, and $2337 \mathrm{~Pa}$ vapor pressure). Then, permeation cells were held in a desiccator under continuous air circulation, and cells weight (g) was checked every $2 \mathrm{~h}$ until steady-state was attained. The WVP $\left(\mathrm{g} \mathrm{m}^{-1} \mathrm{~s}^{-1} \mathrm{~Pa}^{-1}\right)$ of the $\mathrm{BCm}$-based films was determined as follows:

$$
W V P=\frac{W V T R \times L}{\Delta P}
$$

where $W V T R=$ water vapor transmission rate $\left(\mathrm{g} \mathrm{m}^{-1} \mathrm{~s}^{-1} \mathrm{~Pa}^{-1}\right) ; L=$ mean film thickness $(\mathrm{m}) ;$ and $\Delta P$ $=$ partial difference of vapor pressure $(\mathrm{Pa})$ between the two sides of the film.

\subsubsection{Moisture Content and Water Solubility}

$\mathrm{BCm}$-based films (2-cm diameter) initial weight $\left(W_{0}\right)$ was determined, then they were carried at constant weight using a drying oven at $105{ }^{\circ} \mathrm{C}$ to register the film sample final weight $\left(W_{1}\right)$. The percentage of moisture content (\%) was measured according to the subsequent equation:

$$
\text { Moisture content }(\%)=\frac{W_{0}-W_{1}}{W_{0}} \times 100
$$

The water solubility was determined as the dry film matter percentage dissolved following distilled water immersion during $24 \mathrm{~h}$ [14]. For this, previously dried films presenting an initial weight $\left(W_{1}\right)$ were dipped in $50 \mathrm{~mL}$ distilled water under gentle shaking for $24 \mathrm{~h}$ at $20^{\circ} \mathrm{C}$. The samples were filtered using polyester cloth meshes, and insoluble film fragments were dried to constant weight $\left(W_{2}\right)$ at $105^{\circ} \mathrm{C}$ in an oven. The percentage of water solubility (\%) was calculated as follows:

$$
\text { Water solubility }(\%)=\frac{W_{1}-W_{2}}{W_{1}} \times 100
$$

where $W_{1}$, and $W_{2}$ represent the initial and insoluble dry matter, respectively. Three repetitions per experiment were performed.

\subsubsection{Optical Properties}

A previously calibrated Minolta CR-400 colorimeter (Minolta Co. Ltd., Osaka, Japan) with a white color plate as standard $(Y=93.5, x=0.3114, y=0.3190)$ was used to estimate the BCm-based films' 
color properties. Then, CIE $L^{*} a^{*} b^{*}$ scale was used to measure $L^{*}$ (lightness), $a^{*}$ (red-green), and $b^{*}$ (yellow-blue) parameters. The total color difference $(\Delta E)$ was determined as follows:

$$
\Delta E=\sqrt{\left(\Delta L^{*}\right)^{2}+\left(\Delta a^{*}\right)^{2}+\left(\Delta b^{*}\right)^{2}}
$$

where $\Delta L^{*}, \Delta a^{*}$, and $\Delta b^{*}$ are the differences between film sample color parameters $L^{*}, a^{*}$, and $b^{*}$ and white color plate standard. The opacity (\%) was determined according to the Hunter Lab method, as the relationship between film sample opacity on the black color plate standard $\left(Y_{b}\right)$, and the film sample opacity on the white color plate standard $\left(Y_{w}\right)$, as follows:

$$
\text { Opacity }(\%)=\frac{Y_{b}}{Y_{w}} \times 100
$$

Five measurements were taken of each film sample, and three samples of each film were tested for optical properties.

\subsubsection{Mechanical Properties}

Mechanical properties, tensile strength (TS), and elongation-at-break (EB) were measured by means of an Instron Universal Testing Machine (Model 4500, Instron Corporation, Canton, MA, USA), according to the ASTM D882-91 method [20]. Preconditioned film strips $(100 \mathrm{~mm} \times 20 \mathrm{~mm})$ at $20^{\circ} \mathrm{C}$, $53 \% \mathrm{RH}$ were cut and positioned between tensile grips with an initial grip separation of $100-\mathrm{mm}$ and crosshead speed of $5 \mathrm{~mm} \mathrm{~min}{ }^{-1}$. TS and EB were expressed in MPa and \%, respectively. Tests were replicated three times for each film sample.

\subsubsection{Rheology Behavior}

Rheological measurements were carried out by using a stress-controlled rheometer (TA Instruments, New Castle, DE, USA), equipped with concentric cylinders ( $32 \mathrm{~mm}$ height, $13.83 \mathrm{~mm}$ internal diameter, and $15 \mathrm{~mm}$ external diameter) and a cone-plate geometry $\left(60 \mathrm{~mm}\right.$ diameter, $2^{\circ}$ angle, truncation $58 \mu \mathrm{m})$. Evaluations were conducted in triplicate at $25^{\circ} \mathrm{C}$ with a shear rate range of 0 to $100 \mathrm{~s}^{-1}$. The experimental results (shear stress-shear rate) were fitted to the Herschel-Bulkley model:

$$
\sigma=\sigma_{0}+k \dot{\gamma}^{n}
$$

where $\sigma$ is the shear stress $(\mathrm{Pa}), \sigma_{0}$ is the yield stress $(\mathrm{Pa}), k$ is the consistency index $\left(\mathrm{Pa} \mathrm{s}^{n}\right), \dot{\gamma}$ is the shear rate $\left(\mathrm{s}^{-1}\right)$, and $n$ is the flow index.

\subsection{Statistical Analyses}

Data were analyzed using the program StatSoft, Inc. (2011) and Microsoft Excel (Office 365) software. Tukey's test was applied and differences between treatments at $p<0.05$ were considered significant. The Probit analysis (SAS Program Version 9.1) was used to estimate the minimum Rm fruit extract inhibitory concentration that causes a 50\% and 90\% reduction in fungal growth $\left(\mathrm{MIC}_{50}\right.$ and $\mathrm{MIC}_{90}$, respectively) at $p<0.0001$ significant level.

\section{Results and Discussion}

\subsection{Characterization and Bioactivity of Rm Fruit Extracts}

The effect of the solvent used in the recovery of phenolic compounds, and the direct relationship of these with the plant extracts' bioactivity, have been widely reported [2,21]. For example, Wu et al. [22] found higher TPC for ethanol extracts from $R$. hirta L. fruit that those from water extracts (81.6 and $46.3 \mathrm{~g} \mathrm{GA} \mathrm{kg}^{-1}$ extract, respectively). In contrast, Bursal and Köksal [23] detected higher TPC for R. coriaria L. fruit aqueous extracts when compared to those extracted with ethanol (63.0 and $15.0 \mathrm{~g}$ GA 
$\mathrm{kg}^{-1}$ extract, respectively). In this study, the influence of the solvent was not significant $(p>0.05)$ in the TPC (Table 1). But it had a significant effect $(p<0.05)$ on the phenolic profile by UHPLC, and on the antioxidant and antifungal activities.

Table 1. Characterization of R. microphylla (Rm) fruit extracts.

\begin{tabular}{ccc}
\hline & AE & HAE \\
\hline Total phenolic content, TPC $\left(\mathrm{g} \mathrm{GA} \mathrm{kg}^{-1}\right.$ extract $)$ & $146.8 \pm 0.1^{\mathrm{a}}$ & $151.0 \pm 3.9^{\mathrm{a}}$ \\
Antiradical activity, $\left(C_{50}\left(\mathrm{mg} \mathrm{L}^{-1}\right)\right.$ & $130.0 \pm 10.0^{\mathrm{b}}$ & $170.0 \pm 10.0^{\mathrm{a}}$ \\
Phenolic compound $\left(\mathrm{mg} \mathrm{L}^{-1}\right)$ & & \\
Catechin & n.d. & $10.4 \pm 0.4$ \\
Ferulic acid & $5.7 \pm 0.1^{\mathrm{a}}$ & $6.1 \pm 1.3^{\mathrm{a}}$ \\
Gallic acid & $203.2 \pm 0.7^{\mathrm{a}}$ & $98.6 \pm 4.4^{\mathrm{b}}$ \\
p-coumaric acid + epicatechin & $7.4 \pm 0.2^{\mathrm{b}}$ & $78.2 \pm 1.5^{\mathrm{a}}$ \\
Ellagic acid & n.d. & $2.9 \pm 0.1$ \\
Apigenin & n.d. & $0.3 \pm 0.0$ \\
Quercetin & n.d. & $2.1 \pm 0.0$ \\
Resveratrol & n.d. & $2.9 \pm 0.0$ \\
\hline
\end{tabular}

$\mathrm{AE}$, aqueous; HAE, hydro-alcohol extracts; n.d.: not detected. The results were obtained using correction factors from the initial concentration. Values in the same row followed by different letters $\left({ }^{\mathrm{a}-\mathrm{b}}\right)$ are significantly different $(p$ $<0.05)$.

The AE showed higher $(p<0.05)$ antioxidant potential that HAE $(130.0 \pm 10.0$ and $170 \pm 10.0 \mathrm{mg}$ $\mathrm{L}^{-1}$, respectively), as it is known that lower values of $I C_{50}$ indicate a more potent antioxidant activity [9]. These results are in agreement with those reported for $R$. tripartitum fruit extracts ( 33.5 to $223.3 \mathrm{mg} \mathrm{L}^{-1}$ ). Concerning the phenolic profile by UHPLC, the effect of the solvent used in the composition of each extract was evident (Table 1). The HAE presented eight phenolic compounds of diverse nature, whilst in the AE only three compounds were detected. The GA was the most abundant compound in both extracts, being 2-fold higher $(p<0.05)$ for the AE $\left(203.2 \pm 0.7 \mathrm{mg} \mathrm{L}^{-1}\right)$ than the HAE $\left(98.6 \pm 4.4 \mathrm{mg} \mathrm{L}^{-1}\right)$. The mixture of $p$-coumaric acid + epicatechin was the second in concentration order $(78.2 \pm 1.5$ and $7.4 \pm 0.2 \mathrm{mg} \mathrm{L}^{-1}$, for HAE and AE, respectively). These compounds are presented as a mixture, since their retention time were the same as reported by Jesus et al. [19]. Moreover, flavonoids (catechin, apigenin, and quercetin), phenolic acids (ellagic and ferulic acids), and a stilbene (resveratrol) were found in minor quantities in HAE. These phenolic compounds can exhibit a wide range of bioactivities individually, such as antioxidant, antibacterial, antifungal, anti-cancer, anti-inflammatory, apoptotic, nutraceutical, and therapeutic effects, among others [2,21]. Therefore, it is indicative of the promising potential of the Rm extracts, mainly of HAE. This is the first time that the phenolic profile of Rm fruit extracts is reported.

Moreover, the results of antifungal activity on fungi of commercial importance were concentration-dependent showing significant differences $(p<0.05)$ from concentrations higher than $1000 \mathrm{mg} \mathrm{L}^{-1}$ (Figure 1). The HAE presented the highest inhibitory effect on both fungi with a mean inhibition around $60 \%$ at $2500 \mathrm{mg} \mathrm{L}^{-1}$ on F. oxysporum, and $100 \%$ of inhibition on C. cassiicola at $3000 \mathrm{mg} \mathrm{L}^{-1}$. These results were reflected on MICs values (Table 2), as the HAE showed an enhanced effect on C. cassiicola with minor $\mathrm{MIC}_{50}$ and $\mathrm{MIC}_{90}$ values (1802.9 and $3086.3 \mathrm{mg} \mathrm{L}^{-1}$, respectively) when compared to those obtained for F. oxysporum (2522.5 and $4251.1 \mathrm{mg} \mathrm{L}^{-1}$, respectively). Jasso de Rodríguez et al. [6] reported lower antifungal effect of $R$. muelleri leaves ethanol extracts on F. oxysporum, as they obtained higher MICs values (MIC 50 and $\mathrm{MIC}_{90}$ values of 3363 and 11,793 $\mathrm{mg} \mathrm{L}^{-1}$, respectively) than those found for Rm fruit HAE. Such an effect can be attributed to the phenolic compounds identified in the Rm fruit extracts, which can probably act in synergy (Table 1). 


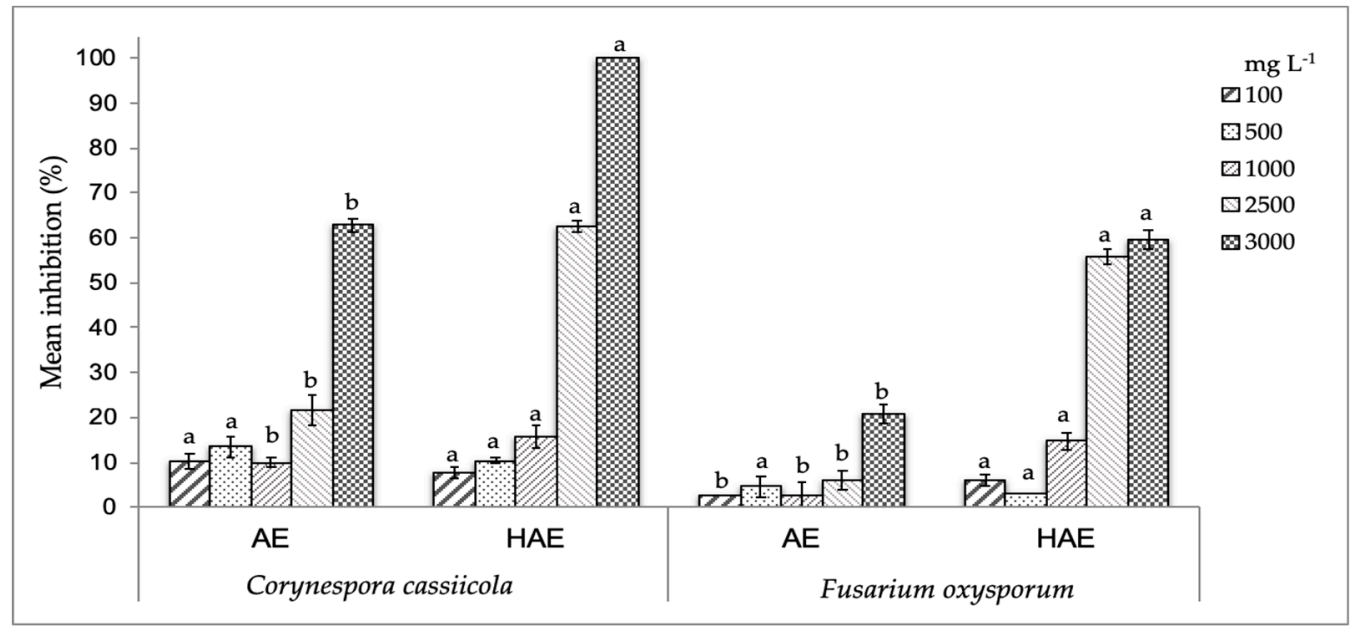

Figure 1. Mean antifungal activity (\%) of R. microphylla (Rm) fruit extracts (AE, aqueous; and HAE, hydro-alcohol extracts) against $C$. cassiicola and F. oxysporum. Values at the same extract concentration with different letters $\left({ }^{\mathrm{a}-\mathrm{b}}\right)$ are significantly different $(p<0.05)$.

Table 2. Minimum inhibitory concentrations (MICs) of R. microphylla (Rm) fruit extracts that causes a $50 \%$ and $90 \%$ reduction in the growth of F. oxysporum and C. cassiicola.

\begin{tabular}{|c|c|c|c|c|c|c|}
\hline \multirow{2}{*}{ Extracts } & \multicolumn{4}{|c|}{ 95\% Fiducial Limits } & \multicolumn{2}{|c|}{ 95\% Fiducial Limits } \\
\hline & $\mathrm{MIC}_{50}\left(\mathrm{mg} \mathrm{L}^{-1}\right)$ & Lower & Upper & $\mathrm{MIC}_{90}\left(\mathrm{mg} \mathrm{L}^{-1}\right)$ & Lower & Upper \\
\hline \multicolumn{7}{|c|}{ F. oxysporum } \\
\hline $\mathrm{AE}$ & 5780.8 & 5387.8 & 6173.8 & 9314.5 & 8909.0 & 9719.9 \\
\hline HAE & 2522.5 & 2093.2 & 3181.8 & 4251.1 & 3493.4 & 5874.3 \\
\hline \multicolumn{7}{|c|}{ C. cassiicola } \\
\hline $\mathrm{AE}$ & 3116.7 & 2901.7 & 3331.7 & 5741.2 & 5524.9 & 5957.5 \\
\hline HAE & 1802.9 & 978.4 & 2935.5 & 3086.3 & 2256.3 & 6268.0 \\
\hline
\end{tabular}

$\mathrm{AE}$, aqueous; and HAE, hydro-alcohol extracts.

It is noteworthy that even when AE showed higher GA concentrations, a compound with proved antifungal effect [24], this extract exhibited the lowest effectiveness. This reveals that the antifungal action is related not only to a compound but also to the structure and interaction between the components of the plant extract matrix $[25,26]$. Therefore, the HAE can be a good alternative for the management of F. oxysporum and C. cassiicola, very aggressive and devastating fungi in the field, the damage caused by which usually extends to the fruit in the post-harvest stage [27,28].

Since the HAE presented an outstanding phenolic profile with good antioxidant activity, and considering its higher antifungal effect, the HAE at $2500 \mathrm{mg} \mathrm{L}^{-1}$ was selected to be incorporated into the $\mathrm{BCm}$-based films for subsequent characterization studies.

\subsection{Film Characterization}

\subsubsection{Surface Tension and Zeta Potential}

In general, addition of the bioactive extract decreased $(p<0.05)$ the surface tension of the filmogenic solutions (Table 3). Typically, surfactants such as Tween 80 are used to reduce surface tension and, thus, the solutions' wettability towards the surface to be coated is favored [29]. In this work, such an effect was achieved with HAE incorporation. This may be due to phenolic compounds' hydroxyl groups detected in the HAE that allowed a better interaction between the filmogenic solutions' components, as an improved polar groups arrangement in the surface layer is achieved in comparison with their non-functionalized counterparts [30]. Torres-León et al. [10] reported similar behavior, when 
antioxidant mango seed extract reduced the surface tension of mango by-products coating forming solution from 57.8 to $52.2 \mathrm{mN} \mathrm{m}^{-1}$, improving its adhesion to the peach fruit.

Table 3. Surface tension, zeta potential (Zp), water vapor permeability (WVP), moisture content, and solubility of black chia seed mucilage $(\mathrm{BCm})$-based films.

\begin{tabular}{|c|c|c|c|c|c|}
\hline $\begin{array}{c}\text { Film } \\
\text { Formulation }\end{array}$ & $\begin{array}{c}\text { Surface } \\
\text { tension } \\
\left.(\mathrm{mN} \mathrm{m})^{-1}\right)\end{array}$ & $\underset{(\mathrm{mV})}{\mathrm{Zp}}$ & $\begin{array}{c}\text { WVP } \times 10^{-10} \\
\left(\mathrm{~g} \mathrm{~m}^{-1} \mathrm{~s}^{-1} \mathrm{~Pa}^{-1}\right)\end{array}$ & $\begin{array}{l}\text { Moisture } \\
\quad(\%)\end{array}$ & $\begin{array}{c}\text { Solubility } \\
(\%)\end{array}$ \\
\hline BCm0.2 & $51.6 \pm 0.4^{\mathrm{a}}$ & $-33.3 \pm 2.8^{\mathrm{a}}$ & $3.7 \pm 0.2^{\mathrm{a}}$ & $81.0 \pm 1.7^{\mathrm{a}}$ & $15.0 \pm 3.3^{\mathrm{a}}$ \\
\hline BCm0.4 & $50.6 \pm 0.2^{\mathrm{a}}$ & $-34.4 \pm 3.0^{\mathrm{a}}$ & $3.7 \pm 0.1^{\mathrm{a}}$ & $68.4 \pm 1.3^{c}$ & $25.0 \pm 2.4^{\mathrm{a}}$ \\
\hline $\mathrm{BCm} 0.2+\mathrm{Rm}$ & $43.0 \pm 0.8^{b}$ & $-32.8 \pm 3.8^{\mathrm{a}}$ & $3.8 \pm 0.2^{\mathrm{a}}$ & $79.0 \pm 0.7^{b}$ & $23.3 \pm 1.5^{\mathrm{a}}$ \\
\hline $\mathrm{BCm} 0.4+\mathrm{Rm}$ & $43.9 \pm 1.6^{\mathrm{b}}$ & $-26.9 \pm 3.4^{\mathrm{a}}$ & $4.0 \pm 0.2^{\mathrm{a}}$ & $66.0 \pm 0.9^{\mathrm{d}}$ & $27.3 \pm 4.3^{\mathrm{a}}$ \\
\hline
\end{tabular}

Rm: hydro-alcohol extract of R. microphylla fruit at $2500 \mathrm{mg} \mathrm{L}^{-1}$. Values in the same column followed by different letters $\left.{ }^{\mathrm{a}-\mathrm{d}}\right)$ are significantly different $(p<0.05)$. Values reported are the mean \pm standard deviation.

The $\mathrm{Zp}$ is an important parameter to determine the surface charge of a filmogenic solution, in order to evaluate its stability and predict its mode of interaction with the surface to be coated [8]. The Zp results showed that the formulations had a negative charge, confirming the polyanionic nature of the $\mathrm{BCm}$-based solutions [15] (Table 3). The results were higher (in the range of -26.9 to $-33.3 \mathrm{mV}$ ) than those reported for formulations based on pectin $(-17.8 \mathrm{mV})$, also an anionic polymer [31]. This feature allowed $\mathrm{BCm}$ to form films as a result of interaction with $\mathrm{Ca}^{2+}$ cations, and when the solvent evaporated, a film matrix was produced [32]. Interestingly, the formulations did not show significant changes in the $\mathrm{Zp}$ values after functionalization nor were they influenced by the $\mathrm{BCm}$ concentration, maintaining their suitable stability.

\subsubsection{Water Vapor Permeability (WVP)}

The main objective of food packaging is to prevent or reduce water loss due to its direct relation with deteriorative reactions, therefore low WVP values are desirable [11]. Table 3 shows the WVP results of semi-permeable BCm-based films, which are in the range of $3.7-4.0 \times 10^{-10} \mathrm{~g} \mathrm{~m}^{-1} \mathrm{~s}^{-1}$ $\mathrm{Pa}^{-1}$. These results were consistent with those reported for blends of $\mathrm{Cm}$, whey protein, and glycerol $\left(1.9 \times 10^{-10} \mathrm{~g} \mathrm{~m}^{-1} \mathrm{~s}^{-1} \mathrm{~Pa}^{-1}\right)$ [15]. They also agree with WVP values $\left(1.2 \times 10^{-10} \mathrm{~g} \mathrm{~m}^{-1} \mathrm{~s}^{-1} \mathrm{~Pa}^{-1}\right)$ found by Dick et al. [14], although they used higher $\mathrm{Cm}$ and glycerol concentrations (1\% w/v and $75 \%, \mathrm{w} / \mathrm{v}$, respectively). It is worth noting that WVP did not change $(p>0.05)$ with bioactive extract incorporation. Similarly, Costa et al. [12] reported that wheat bran arabinoxylans incorporation in chitosan-based films did not show significant influence on WVP, but they have a positive effect on other parameters (e.g., mechanical properties' improvement). The results obtained indicate that it is feasible to incorporate HAE (at the concentration used) in BCm-based films without altering their WVP. Moreover, the semi-permeable character of these films could make them optimal for application in climacteric crops (e.g., avocado, papaya, mango), in which gas exchange $\left(\mathrm{CO}_{2} / \mathrm{O}_{2}\right)$ is necessary, while restricting the production of ethylene [1].

\subsubsection{Moisture Content and Water Solubility}

The moisture content and water solubility of $\mathrm{BCm}$-based films are also shown in Table 3. All the films presented higher moisture content (within the range of $66.0 \%-80.9 \%$ ) than that obtained for films using chia as matrix ( $36.6 \%$ to $41.9 \%$ on average) [14,15], which indicates their high biodegradability capacity [13]. These results could be due to the high $\mathrm{BCm}$ absorption properties [33], which in combination with calcium ions and glycerol, forms a network with greater ability to trap water in its structure. HAE incorporation into films significantly decreased $(p<0.05)$ the moisture content and more compact film surfaces were observed (data not shown), exhibiting that functionalization influenced the film's water affinity properties. 
On the other hand, films solubility was not changed $(p>0.05)$ with the bioactive extract addition, all films being partially soluble (solubility around $15.0 \%$ to $22.3 \%$ ). These results suggest the high stability of the forming matrix. However, they do not agree to those previously reported for Cm-based films, which usually have higher solubility values (in the range of $48 \%-80 \%$ ) associated to the $\mathrm{Cm}$ hydrophilic nature [13-15]. The high-water films' resistance obtained in this work can be a result of a better interaction of their components (mucilage-calcium-glycerol), making those interesting materials to be applied in high-humidity foods (e.g., fresh-cut fruits) [34].

\subsubsection{Optical Properties}

The color and opacity are crucial edible film parameters, which influence product acceptability and consumer perception [14]. Color results showed that bioactive extract incorporation produced significantly darker (lower $L^{*}$ values) films, while films presented higher $(p<0.05) \Delta E$ values (Table 4 ). Also, their functionalization led to a significant increase $(p<0.05)$ in color variation between red-green $\left(a^{*}\right)$ and yellow-blue $\left(b^{*}\right)$. These observations could be due to the pigments' red-brownish coloration present in Rm fruit. The results obtained agree with the findings of Fabra et al. [35], which indicated that polyphenols present in green tea and grape seed natural extracts imparted color and provided different light barrier properties to alginate edible films.

Table 4. Color parameters of BCm-based films.

\begin{tabular}{cccccc}
\hline Film Formulation & $\boldsymbol{L}^{*}$ & $\boldsymbol{a}^{*}$ & $\boldsymbol{b}^{*}$ & Opacity (\%) & $\boldsymbol{\Delta} \boldsymbol{E}$ \\
\hline BCm0.2 & $92.3 \pm 0.3^{\mathrm{a}}$ & $0.4 \pm 0.1^{\mathrm{d}}$ & $10.2 \pm 0.6^{\mathrm{d}}$ & $5.2 \pm 0.3^{\mathrm{c}}$ & $12.3 \pm 0.4^{\mathrm{d}}$ \\
BCm0.4 & $85.4 \pm 0.5^{\mathrm{b}}$ & $1.8 \pm 0.1^{\mathrm{c}}$ & $17.8 \pm 0.4^{\mathrm{c}}$ & $6.3 \pm 0.4^{\mathrm{b}}$ & $17.3 \pm 0.4^{\mathrm{c}}$ \\
BCm0.2+Rm & $83.6 \pm 0.6^{\mathrm{c}}$ & $4.5 \pm 0.3^{\mathrm{b}}$ & $29.8 \pm 1.0^{\mathrm{b}}$ & $4.5 \pm 0.2^{\mathrm{d}}$ & $29.6 \pm 1.0^{\mathrm{b}}$ \\
BCm0.4+Rm & $79.8 \pm 0.8^{\mathrm{d}}$ & $5.6 \pm 0.4^{\mathrm{a}}$ & $32.1 \pm 0.8^{\mathrm{a}}$ & $6.8 \pm 0.3^{\mathrm{a}}$ & $32.4 \pm 1.0^{\mathrm{a}}$ \\
\hline
\end{tabular}

Rm: hydro-alcohol extract of $R$. microphylla fruit at $2500 \mathrm{mg} \mathrm{L}^{-1}$. Values in the same column followed by different letters $\left({ }^{\mathrm{a}-\mathrm{d}}\right)$ are significantly different $(p<0.05)$.

Regarding film opacity, this increased $(p<0.05)$ with $\mathrm{BCm}$ concentration growth. However, the HAE addition significantly altered the opacity values of the films, when compared to their non-functionalized counterparts. This shows that the interaction between phenol compounds and BCm plays an essential role in the films' optical properties obtained in this work [11,12].

\subsubsection{Film Thickness and Mechanical Properties}

The thickness directly affects edible films' physical, optical, and mechanical properties [20,36]. The films average thickness $(40-60 \mu \mathrm{m})$ was very similar to the values reported by Dick et al. [14], which used $\mathrm{Cm}$ and different glycerol amounts, obtaining values ranging from 54 to $60 \mu \mathrm{m}$. The results showed that film thickness was significantly affected $(p<0.05)$ by BCm concentration and HAE incorporation (Table 5). This has also been confirmed by other researchers $[11,13,30]$, in which there is a relationship between film thickness and polymer concentration and the incorporation of bioactive compounds into the filmogenic solution. This relationship also influenced the mechanical properties of BCm-based films; although relatively low values of TS (0.5-1.6 MPa) and EB (5.5\%-14.0\%) were obtained for all the films (Table 5). According to Arquelau et al. [20], this result can be related to their low thickness and film composition. It is possible that filmogenic matrix components (e.g., sugars, phenolic compounds) are able to act as plasticizer and in combination with glycerol and $\mathrm{BCm}$ fractions, could cause intermolecular forces changes in the system reducing the films' resistance. 
Table 5. Thickness and mechanical properties (tensile strength-TS and elongation at break-EB) of BCm-based films.

\begin{tabular}{cccc}
\hline Film Formulation & Thickness $(\mu \mathrm{m})$ & TS $(\mathbf{M P a})$ & EB $(\%)$ \\
\hline BCm0.2 & $40.0 \pm 0.0^{\mathrm{c}}$ & $0.5 \pm 0.2^{\mathrm{c}}$ & $14.0 \pm 3.0^{\mathrm{a}}$ \\
BCm0.4 & $50.0 \pm 0.0^{\mathrm{b}}$ & $1.1 \pm 0.1^{\mathrm{b}}$ & $9.5 \pm 1.0^{\mathrm{b}}$ \\
BCm0.2+Rm & $50.0 \pm 0.0^{\mathrm{b}}$ & $0.6 \pm 0.0^{\mathrm{c}}$ & $5.5 \pm 0.5^{\mathrm{c}}$ \\
BCm0.4+Rm & $60.0 \pm 0.0^{\mathrm{a}}$ & $1.6 \pm 0.4^{\mathrm{a}}$ & $7.2 \pm 1.4^{\mathrm{bc}}$ \\
\hline
\end{tabular}

Rm: hydro-alcohol extract of R. microphylla fruit at $2500 \mathrm{mg} \mathrm{L}^{-1}$.Values in the same column followed by different letters $\left({ }^{\mathrm{a}-\mathrm{c}}\right)$ are significantly different $(p<0.05)$. Values reported are the mean \pm standard deviation.

It is noteworthy that the films prepared with the highest $\mathrm{BCm}$ concentration were more resistant than those with the lowest $\mathrm{BCm}$ ratio [15]; highlighting, the $\mathrm{BCm} 0.4+\mathrm{Rm}$ film. As stated by Costa et al. [12], this behavior can be explained by the combination of higher polymer $(\mathrm{BCm})$ concentration and the addition of bioactive extract (HAE) with a lower moisture content into this film, resulting in higher TS values. Meanwhile, HAE addition produced a significant decrease $(p<0.05)$ of EB values when compared with BCm-based films prepared without HAE (Table 5). These changes may be related to the best surface tension results detected for the filmogenic solutions with HAE (Table 3). Hence, homogeneous filmogenic solutions possibly with better adhesion ability associated to reduced EB of BCm-based films functionalized with bioactive extract were formed [30].

\subsubsection{Rheological Behavior}

For application purposes, it is important to consider the rheological properties of the filmogenic solutions, as this allows application methods, sensory qualities, and processing costs to be defined. Table 6 shows the satisfactorily agreement of experimental data to the Herschel-Bulkley model, as values of root square mean error (RSME) were very small and the correlation factor $\left(R^{2}\right)$ was higher than 0.999 . For all the systems, the viscosity declined as shear rate increases, which confirms their pseudoplastic behavior (Figure 2a) [37]. This characteristic is typical of polymer solutions, and it is the result of the random molecular arrangement within the structure of the biopolymer in response to the flow, therefore, the viscosity tends to decrease [32,38]. Similar results have been reported for dispersions of chia [32], flaxseed gum [37], and blends of poly(vinyl) alcohol with itaconic acid and chitosan [38]. The pseudoplastic nature was also corroborated as all solutions showed values of flow behavior index $(n)$ lower than 1 . The consistency index $(k)$ parameter was significantly higher $(p<0.05)$ for the solutions with higher concentration of $\mathrm{BCm}$, showing a clear relationship with mucilage concentration [32]. This implication can be derived from the Herschel-Bulkley model, as the $k$ index is associated with the viscous nature [39]. Apparently, higher $k$ values indicate a better arrangement of the systems (inter or intramolecularly) associated with their nature and structural conformation. Moreover, an increase in the intensity of shear-thinning behavior was observed, since $n$ values significantly decreased as a consequence of the $\mathrm{BCm}$ concentration growth. However, it should be noted that the addition of HAE did not influence $(p>0.05)$ the rheological properties (Figure 2b). This is interesting, since it is possible to have the functionality derived from the bioactive extract without altering the rheological behavior of the systems. 
Table 6. Rheological parameters of Herschel-Bulkley model for BCm-based filmogenic solutions.

\begin{tabular}{ccccc}
\hline Film Formulation & $\boldsymbol{n}$ & $\boldsymbol{k}\left(\mathbf{P a ~ s}^{\boldsymbol{n}} \mathbf{)}\right.$ & $\boldsymbol{R}^{\mathbf{2}}$ & $\boldsymbol{R}$ RME \\
\hline BCm0.2 & $0.86 \pm 0.00^{\mathrm{a}}$ & $0.02 \pm 0.00^{\mathrm{b}}$ & 0.999 & $0.6 \times 10^{-4}$ \\
BCm0.4 & $0.70 \pm 0.00^{\mathrm{b}}$ & $0.09 \pm 0.01^{\mathrm{a}}$ & 0.999 & $1.3 \times 10^{-4}$ \\
$\mathrm{BCm} 0.2+\mathrm{Rm}$ & $0.87 \pm 0.04^{\mathrm{a}}$ & $0.02 \pm 0.01^{\mathrm{b}}$ & 0.998 & $1.1 \times 10^{-4}$ \\
BCm0.4+Rm & $0.70 \pm 0.00^{\mathrm{b}}$ & $0.08 \pm 0.01^{\mathrm{a}}$ & 0.999 & $1.4 \times 10^{-4}$ \\
\hline
\end{tabular}

Rm: hydro-alcohol extract of R. microphylla fruit at $2500 \mathrm{mg} \mathrm{L}^{-1} ; n$ : flow behavior index; $k$ : consistency index; $R^{2}$ : correlation factor; RSME: root square mean error. Values in the same column followed by different letters $\left({ }^{a-b}\right)$ are significantly different $(p<0.05)$. Values reported are the mean \pm standard deviation.

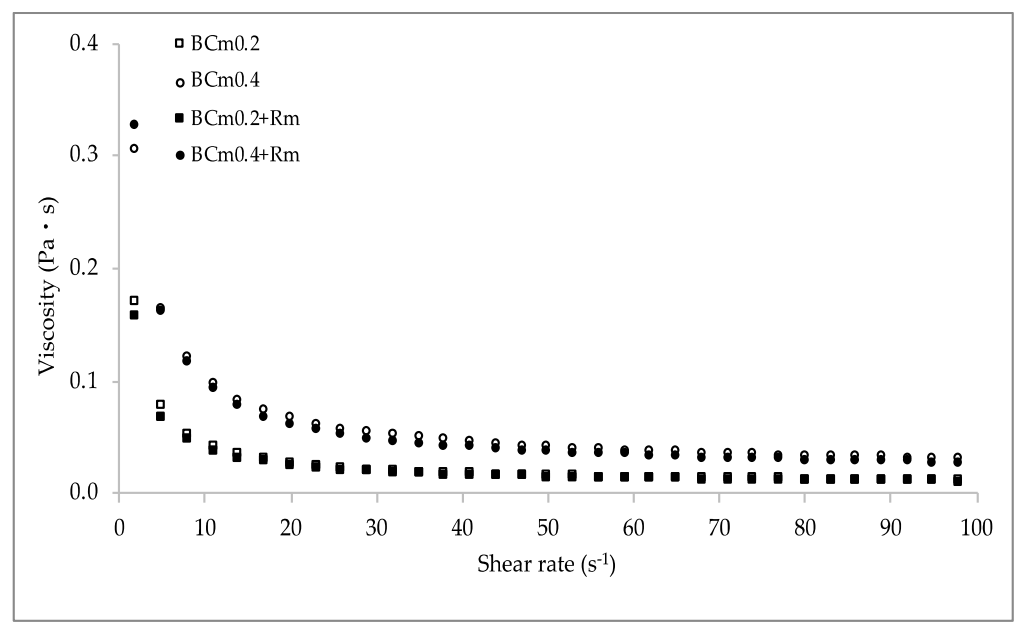

(a)

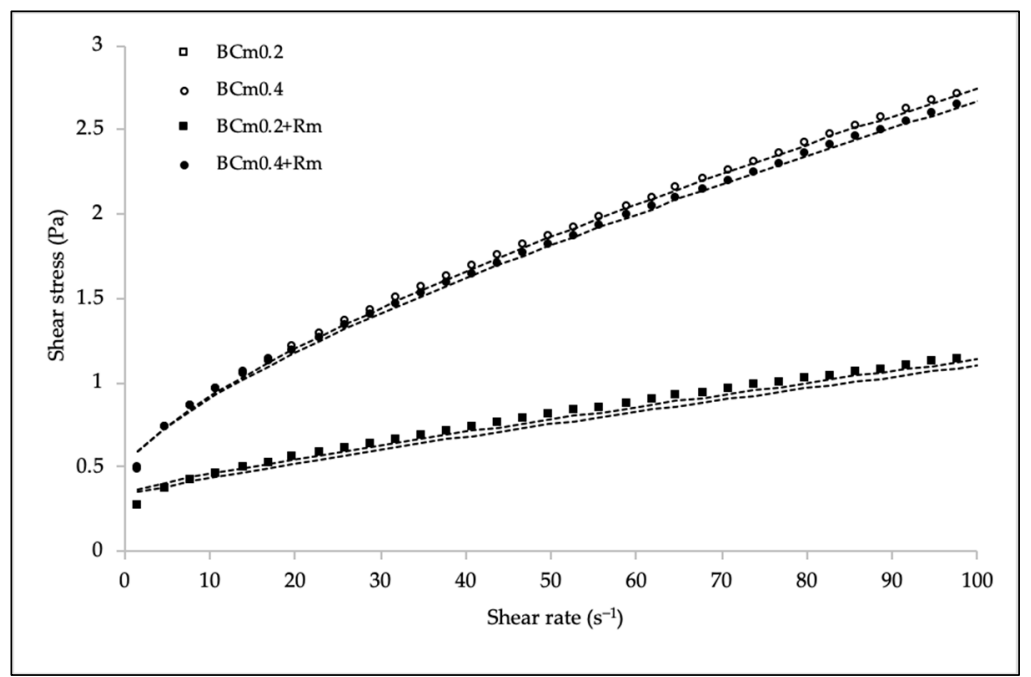

(b)

Figure 2. Viscosity (a) and steady shear rate flow (b) at $25{ }^{\circ} \mathrm{C}$ for $\mathrm{BCm}$-based filmogenic solutions with and without (-Rm) hydro-alcohol extract (HAE) of R. microphylla fruit at $2500 \mathrm{mg} \mathrm{L}^{-1}$. Lines (.....) correspond to the Herschel-Bulkley model.

The active $\mathrm{BCm}$-based edible films functionalized with $\mathrm{Rm}$ fruit HAE presented attractive properties; however, future work is required to evaluate their potential application. Besides, it is necessary to study HAE bioactivity within the film and the release of bioactive compounds from the film to the produce surface. This work is the first to show the potential Rm fruit HAE to be added to biodegradable chia-based edible films. 


\section{Conclusions}

Functional BCm-based films were successfully produced with Rm fruit HAE as antifungal and antioxidant agent. The HAE was selected as it showed interesting phenolic composition, good antioxidant activity, and higher antifungal effect against phytopathogenic fungi of commercial importance, i.e., F. oxysporum and C. cassiicola. The BCm-based solutions exhibited a pseudoplastic and shear-thinning character, showing a good fit with the Herschel-Bulkley model. Besides, they presented a polyanionic nature, which favored the formation of films by interaction with calcium ions, thus obtaining semi-permeable and moderate water-solubility films. The filmogenic solutions' surface tension was improved by HAE addition, while their rheological properties were not $(p>0.05)$ altered, and their moisture content was significantly reduced. However, all the films showed higher moisture than those reported in some studies, revealing their high biodegradability capacity. Regarding optical properties, the films containing HAE were significantly darker and red-brownish in color than films without HAE. Meanwhile, the combination of higher $\mathrm{BCm}$ concentration and HAE incorporation (BCm0.4 + Rm) led to more resistant, thicker, opaque and darker film, as well as with lower moisture content, which could be attributed to a better intermolecular interaction between film components.

The use of these novel systems present advantages because they can provide an additional protection for the produce (i.e., antifungal and antioxidant), while imparting interesting water-barrier, optical, mechanical, and rheological properties. Additional investigations still have to be performed to determine their potential application, for example, as a post-harvest technology for fruit and vegetables.

Author Contributions: Conceptualization, investigation, resources and supervision, A.V.C.-R., A.A.V., M.L.F.-L.; investigation and methodology and validation, L.L.R.-S., J.T.M., Z.G.; formal analysis, project administration and data curation, A.R.-O., G.L.-G., D.G.M.-V., S.G.-M.; writing-original draft, writing-reviewing and editing, J.T.M., Z.G., A.V.C.-R., M.L.F.-L. All authors have read and agreed to the published version of the manuscript.

Funding: This research received no external funding.

Acknowledgments: Financial support from Universidad Autónoma Agraria Antonio Narro (UAAAN) is gratefully acknowledged by the authors. Zlatina Genisheva thanks to Foundation for Science and Technology (FCT) for the financial support (ref. SFRH/BPD/108868/2015) and to the project COMPETE 2020 (POCI-01-0145-FEDER-029145). This study was supported by FCT under the scope of the strategic funding of UIDB/04469/2020 unit and BioTecNorte operation (NORTE-01-0145-FEDER-000004) funded by the European Regional Development Fund under the scope of Norte2020 - Programa Operacional Regional do Norte. The authors would also like to thank to Pablo Virgen of Biocampo S.A. de C.V. and MSc Fidel Peña-Ramos from UAAAN, for their assistance during this study.

Conflicts of Interest: The authors declare no conflict of interest.

\section{References}

1. Flores-López, M.L.; Cerqueira, M.A.; Jasso de Rodríguez, D.; Vicente, A.A. Perspectives on utilization of edible coatings and nano-laminate coatings for extension of postharvest storage of fruits and vegetables. Food Eng. Rev. 2016, 8, 292-305. [CrossRef]

2. Jasso de Rodríguez, D.; Salas-Méndez, E.d.J.; Rodríguez-García, R.; Hernández-Castillo, F.D.; Díaz-Jiménez, M.L.V.; Sáenz-Galindo, A.; González-Morales, S.; Flores-López, M.L.; Villarreal-Quintanilla, J.A.; Peña-Ramos, F.M.; et al. Antifungal activity in vitro of ethanol and aqueous extracts of leaves and branches of Flourensia spp. against postharvest fungi. Ind. Crops Prod. 2017, 107, 499-508. [CrossRef]

3. Kotan, R.; Cakir, A.; Ozer, H.; Kordali, S.; Cakmakci, R.; Dadasoglu, F.; Dikbas, N.; Aydin, T.; Kazaz, C. Antibacterial effects of Origanum onites against phytopathogenic bacteria: Possible use of the extracts from protection of disease caused by some phytopathogenic bacteria. Sci. Hortic. 2014, 172, 210-220. [CrossRef]

4. De, A.; Bose, R.; Kumar, A.; Mozumdar, S. Worldwide pesticide use. In Targeted Delivery of Pesticides Using Biodegradable Polymeric Nanoparticles; Springer: New Delhi, India, 2014; pp. 5-6.

5. Adwan, G.; Abu-Shanab, B.; Adwan, K. Antibacterial activities of some plant extracts alone and in combination with different antimicrobials against multidrug-resistant Pseudomonas aeruginosa strains. Asian Pac. J. Trop. Med. 2010, 3, 266-269. [CrossRef] 
6. Jasso de Rodríguez, D.; Trejo-González, F.A.; Rodríguez-García, R.; Díaz-Jimenez, M.L.V.; Sáenz-Galindo, A.; Hernández-Castillo, F.D.; Villarreal-Quintanilla, J.A.; Peña-Ramos, F.M. Antifungal activity in vitro of Rhus muelleri against Fusarium oxysporum f. sp. lycopersici. Ind. Crops Prod. 2015, 75, 150-158. [CrossRef]

7. Dolores, L.; Latorre, F.A. Plants used by the Mexican Kickapoo Indians. Econ. Bot. 1977, 31, $340-357$. [CrossRef]

8. Fabra, M.J.; Flores-López, M.L.; Cerqueira, M.A.; Jasso de Rodríguez, D.; Lagaron, J.M.; Vicente, A.A. Layer-by-Layer technique to developing functional nanolaminate films with antifungal activity. Food Bioprocess Technol. 2016, 9, 471-480. [CrossRef]

9. Vieira, J.M.; Flores-López, M.L.; Jasso de Rodríguez, D.; Sousa, M.C.; Vicente, A.A.; Martins, J.T. Effect of chitosan-Aloe vera coating on postharvest quality of blueberry (Vaccinium corymbosum) fruit. Postharvest Biol. Technol. 2016, 116, 88-97. [CrossRef]

10. Torres-León, C.; Vicente, A.A.; Flores-López, M.L.; Rojas, R.; Serna-Cock, L.; Alvarez-Pérez, O.B.; Aguilar, C.N. Edible films and coatings based on mango (var. Ataulfo) by-products to improve gas transfer rate of peach. LWT Food Sci. Technol. 2018, 97, 624-631.

11. Cerqueira, M.A.; Souza, B.W.S.; Martins, J.T.; Teixeira, J.A.; Vicente, A.A. Seed extracts of Gleditsia triacanthos: Functional properties evaluation and incorporation into galactomannan films. Food Res. Int. 2010, 43, 2031-2038. [CrossRef]

12. Costa, M.J.; Cerqueira, M.A.; Ruiz, H.A.; Fougnies, C.; Richel, A.; Vicente, A.A.; Teixeira, J.A.; Aguedo, M. Use of wheat bran arabinoxylans in chitosan-based films: Effect on physicochemical properties. Ind. Crops Prod. 2015, 66, 305-311. [CrossRef]

13. Capitani, M.I.; Matus-Basto, A.; Ruiz-Ruiz, J.C.; Santiago-García, J.L.; Betancur-Ancona, D.A.; Nolasco, S.M.; Tomás, M.C.; Segura-Campos, M.R. Characterization of biodegradable films based on Salvia hispanica L. protein and mucilage. Food Bioprocess Technol. 2016, 9, 1276-1286. [CrossRef]

14. Dick, M.; Costa, T.M.H.; Gomaa, A.; Subirade, M.; Rios, A.D.O.; Flôres, S.H. Edible film production from chia seed mucilage: Effect of glycerol concentration on its physicochemical and mechanical properties. Carbohydr. Polym. 2015, 130, 198-205. [CrossRef] [PubMed]

15. Muñoz, L.A.; Aguilera, J.M.; Rodriguez-Turienzo, L.; Cobos, A.; Diaz, O. Characterization and microstructure of films made from mucilage of Salvia hispanica and whey protein concentrate. J. Food Eng. 2012, 111, 511-518. [CrossRef]

16. Valdivia-López, M.A.; Tecante, A. Chia (Salvia hispanica): A review of native Mexican seed and its nutritional and functional properties. In Advances in Food and Nutrition Research, 1st ed.; Elsevier Inc.: Oxford, UK, 2015; Volume 15, pp. 53-75.

17. de Falco, B.; Fiore, A.; Rossi, R.; Amato, M.; Lanzotti, V. Metabolomics driven analysis by UAEGC-MS and antioxidant activity of chia (Salvia hispanica L.) commercial and mutant seeds. Food Chem. 2018, 254, 137-143. [CrossRef]

18. Jasso De Rodríguez, D.; García-Hernández, L.C.; Rocha-Guzmán, N.E.; Moreno-Jiménez, M.R.; Rodríguez-García, R.; Díaz-Jiménez, M.L.V.; Flores-López, M.L.; Villarreal-Quintanilla, J.A.; Peña-Ramos, F.M.; Carrillo-Lomelí, D.A. Hypoglycemic and anti-inflammatory effects of Psacalium paucicapitatum corms infusions. Ind. Crops Prod. 2017, 107, 482-488. [CrossRef]

19. Jesus, M.S.; Genisheva, Z.; Romaní, A.; Pereira, R.N.; Teixeira, J.A.; Domingues, L. Bioactive compounds recovery optimization from vine pruning residues using conventional heating and microwave-assisted extraction methods. Ind. Crops Prod. 2019, 132, 99-110. [CrossRef]

20. Arquelau, P.B.d.F.; Silva, V.D.M.; Garcia, M.A.V.T.; de Araújo, R.L.B.; Fante, C.A. Characterization of edible coatings based on ripe 'Prata' banana peel flour. Food Hydrocoll. 2018, 89, 570-578. [CrossRef]

21. do Prado, A.C.P.; da Silva, H.S.; da Silveira, S.M.; Barreto, P.L.M.; Vieira, C.R.W.; Maraschin, M.; Ferreira, S.R.S.; Block, J.M. Effect of the extraction process on the phenolic compounds profile and the antioxidant and antimicrobial activity of extracts of pecan nut [Carya illinoinensis (Wangenh) C. Koch] shell. Ind. Crops Prod. 2013, 52, 552-561. [CrossRef]

22. Wu, T.; McCallum, J.L.; Wang, S.; Liu, R.; Zhu, H.; Tsao, R. Evaluation of antioxidant activities and chemical characterisation of staghorn sumac fruit (Rhus hirta L.). Food Chem. 2013, 138, 1333-1340. [CrossRef]

23. Bursal, E.; Köksal, E. Evaluation of reducing power and radical scavenging activities of water and ethanol extracts from sumac (Rhus coriaria L.). Food Res. Int. 2011, 44, 2217-2221. [CrossRef] 
24. Nguyen, D.M.C.; Seo, D.J.; Lee, H.B.; Kim, I.S.; Kim, K.Y.; Park, R.D.; Jung, W.J. Antifungal activity of gallic acid purified from Terminalia nigrovenulosa bark against Fusarium solani. Microb. Pathog. 2013, 56, 8-15. [CrossRef] [PubMed]

25. Osorio, E.; Flores, M.; Hernández, D.; Ventura, J.; Rodríguez, R.; Aguilar, C.N. Biological efficiency of polyphenolic extracts from pecan nuts shell (Carya Illinoensis), pomegranate husk (Punica granatum) and creosote bush leaves (Larrea tridentata Cov.) against plant pathogenic fungi. Ind. Crops Prod. 2010, 31, 153-157. [CrossRef]

26. Rao, A.; Zhang, Y.; Muend, S.; Rao, R. Mechanism of antifungal activity of terpenoid phenols resembles calcium stress and inhibition of the TOR pathway. Antimicrob. Agents Chemother. 2010, 54, 5062-5069. [CrossRef] [PubMed]

27. Ma, D.; Zhu, J.; Jiang, J.; Zhao, Y.; Li, B.; Mu, W.; Liu, F. Evaluation of bioactivity and control efficacy of tetramycin against Corynespora cassiicola. Pestic. Biochem. Physiol. 2018, 152, 106-113. [CrossRef]

28. McGovern, R.J. Management of tomato diseases caused by Fusarium oxysporum. Crop Prot. 2015, 73, 78-92. [CrossRef]

29. Ribeiro, C.; Vicente, A.A.; Teixeira, J.A.; Miranda, C. Optimization of edible coating composition to retard strawberry fruit senescence. Postharvest Biol. Technol. 2007, 44, 63-70. [CrossRef]

30. Hauser, C.; Peñaloza, A.; Guarda, A.; Galotto, M.J.; Bruna, J.E.; Rodríguez, F.J. Development of an active packaging film based on a methylcellulose coating containing murta (Ugni molinae Turcz) leaf extract. Food Bioprocess Technol. 2016, 9, 298-307. [CrossRef]

31. Lo'ay, A.A.; Dawood, H.D. Tolerance of 'Baladi' mandarin fruits to cold storage by postharvest pectin/PVA blend with ascorbic acid treatment. Sci. Hortic. 2019, 256, 108637. [CrossRef]

32. Capitani, M.I.; Corzo-Rios, L.J.; Chel-Guerrero, L.A.; Betancur-Ancona, D.A.; Nolasco, S.M.; Tomás, M.C. Rheological properties of aqueous dispersions of chia (Salvia hispanica L.) mucilage. J. Food Eng. 2015, 149, 70-77. [CrossRef]

33. Steffolani, E.; Martinez, M.M.; León, A.E.; Gómez, M. Effect of pre-hydration of chia (Salvia hispanica L.), seeds and flour on the quality of wheat flour breads. LWT Food Sci. Technol. 2015, 61, 401-406. [CrossRef]

34. Chiumarelli, M.; Hubinger, M.D. Evaluation of edible films and coatings formulated with cassava starch, glycerol, carnauba wax and stearic acid. Food Hydrocoll. 2014, 38, 20-27. [CrossRef]

35. Fabra, M.J.; Falcó, I.; Randazzo, W.; Sánchez, G.; López-Rubio, A. Antiviral and antioxidant properties of active alginate edible films containing phenolic extracts. Food Hydrocoll. 2018, 81, 96-103. [CrossRef]

36. Kurek, M.; Galus, S.; Debeaufort, F. Surface, mechanical and barrier properties of bio-based composite films based on chitosan and whey protein. Food Packag. Shelf Life 2014, 1, 56-67. [CrossRef]

37. Vieira, J.M.; Mantovani, R.A.; Raposo, M.F.J.; Coimbra, M.A.; Vicente, A.A. Effect of extraction temperature on rheological behavior and antioxidant capacity of flaxseed gum. Carbohydr. Polym. 2019, 213, 217-227. [CrossRef]

38. Szabo, K.; Teleky, B.-E.; Mitrea, L.; Călinoiu, L.-F.; Martău, G.-A.; Simon, E.; Varvara, R.-A.; Vodnar, D.C. Active packaging-Poly (Vinyl alcohol) films enriched with tomato by-products extract. Coatings 2020, 10, 141. [CrossRef]

39. Pérez-Orozco, J.P.; Sánchez-Herrera, L.M.; Ortiz-Basurto, R.I. Effect of concentration, temperature, pH, co-solutes on the rheological properties of Hyptis suaveolens L. mucilage dispersions. Food Hydrocoll. 2019, 87, 297-306. [CrossRef]

(C) 2020 by the authors. Licensee MDPI, Basel, Switzerland. This article is an open access article distributed under the terms and conditions of the Creative Commons Attribution (CC BY) license (http://creativecommons.org/licenses/by/4.0/). 